\title{
Predictors of mortality among newborns admitted with perinatal asphyxia at public hospitals in Ethiopia: a prospective cohort study
}

Samuel Dessu ${ }^{1 *}$, Zinabu Dawit ${ }^{2}$, Abebe Timerga ${ }^{3}$ and Muluken Bafa ${ }^{2}$

\begin{abstract}
Introduction: Perinatal asphyxia is a complicated newborn health problem and applies a high contribution to the increased proportion of newborn mortality. It occurs in newborns due to altered breathing or inadequate inhalation and exhalation resulting in reduced oxygen perfusion to certain body tissues and organs. Irrespective of the increased progress in health care towards newborns and implementations in reductions in under-five, infant, and neonatal mortality in the past 10 years, perinatal asphyxia remained as the most common severe newborn health challenge that causes a high number of morbidity and mortality.
\end{abstract}

Methods: A prospective cohort longitudinal study was implemented among 573 newborns admitted with perinatal asphyxia at public hospitals in Southern Ethiopia from 1st March 2018 to 28th February 2020. The perinatal survival time was determined using Kaplan Meier survival curve together with a log-rank test. The dependent variable was time to death and the independent variables were classified as socio-demographic factors, obstetrics related factors, newborn related factors and maternal medical related factors. The study subjects were entered in to the cohort during admission with perinatal asphyxia in the hospital and followed until 7 days of life.

Results: The cumulative proportion of survival among the newborns admitted with perinatal asphyxia was $95.21 \%$ (95\%Cl:91.00,97.48), 92.82\% (95\%Cl:87.95,95.77), 92.02\%(95\%Cl:86.84,95.22) and 90.78\%(95\%Cl:84.82,94.48) at the end of first, second, third and fourth follow-up days respectively. The mean survival date was $6.55(95 \% \mathrm{Cl}: 6.33,6.77)$ and cord prolapse (AHR:6.5;95\%Cl:1.18,36.01), pregnancy induced hypertension (AHR:25.4;95\%Cl:3.68,175.0), maternal iron deficiency anemia (AHR:5.9;95\%Cl:1.19,29.5) and having convulsion of the newborn (AHR:10.23;95\%Cl:2.24,46.54) were statistically significant in multivariable cox proportional hazard model.

Conclusion: The survival status among newborns with perinatal asphyxia was low during the early follow-up periods after admission to the hospital and the survival status increased after fourth follow up days. In addition, cord prolapse, history of $\mathrm{PIH}$, maternal iron deficiency anemia and newborns history of convulsion were the independent predictors of mortality.

Keywords: Perinatal asphyxia, prospective study, Predictor of mortality, Southern Ethiopia

\footnotetext{
* Correspondence: dessusamuel@yahoo.com

'Department of Public Health, College of Medicine and Health Sciences, Wolkite University, Wolkite, Ethiopia

Full list of author information is available at the end of the article
}

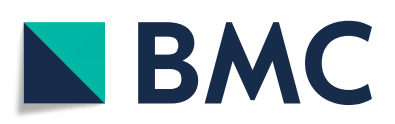

(0) The Author(s). 2021 Open Access This article is licensed under a Creative Commons Attribution 4.0 International License, which permits use, sharing, adaptation, distribution and reproduction in any medium or format, as long as you give appropriate credit to the original author(s) and the source, provide a link to the Creative Commons licence, and indicate if changes were made. The images or other third party material in this article are included in the article's Creative Commons licence, unless indicated otherwise in a credit line to the material. If material is not included in the article's Creative Commons licence and your intended use is not permitted by statutory regulation or exceeds the permitted use, you will need to obtain permission directly from the copyright holder. To view a copy of this licence, visit http://creativecommons.org/licenses/by/4.0/ The Creative Commons Public Domain Dedication waiver (http://creativecommons.org/publicdomain/zero/1.0/) applies to the data made available in this article, unless otherwise stated in a credit line to the data. 


\section{Introduction}

Perinatal asphyxia is a complicated newborn health problem and applies a high contribution to the increased proportion of newborn mortality [1]. It is a leading cause of morbidity and mortality in newborn babies globally, with higher case fatality rates and consequent complications in developing countries due to poor health facilities $[2,3]$. Globally, around 2,500,000 child deaths were reported in the early 28 days of age (neonatal age). These accounts for nearly $47 \%$ of under-five mortality and $54 \%$ of all under-five deaths occur during this age in developing countries [4].

However, greater than $2 / 3$ rd of newborns can be saved through established maternal and newborn health intervention programs. Though, most of the observed deaths have occurred at home delivered newborns [5]. Nearly 3.6 million (3\%) of all infants suffer from a certain level of perinatal asphyxia. Among this 840,000 (23\%) will die and approximately a similar proportion of newborns develop life-threatening health problems in developing countries [6, 7].

Globally, around 25\% of all newborn mortality is caused by perinatal asphyxia [8]. The study conducted at public hospitals in Ethiopia indicated that, perinatal asphyxia contributed to $28.35 \%$ of newborn deaths and prematurity and neonatal sepsis accounted for 28.85 and $18.35 \%$ respectively $[9,10]$.

Irrespective of the increased advancements in perinatal care and implementations in reductions of under-five, infant and neonatal mortality in the past decades $[4,11$, 12], perinatal asphyxia remains a severe newborn health problem causing a high number of mortality and morbidity and is a major common public health issue, commonly in developing countries like Ethiopia [13].

Even though Ethiopia reached its child mortality reduction goal 2 years earlier, the neonatal mortality rate remained high. One of the major causes of newborn deaths was intrapartum-related complications of which birth asphyxia accounts for $25 \%[10,14]$.

Moreover, a very limited number of studies were conducted in Ethiopia to identify information for intervention regarding the death due to perinatal asphyxia. Therefore; this study was planned to estimate the time to death and its predictors among newborns with perinatal asphyxia at governmental hospitals in Southern Ethiopia.

\section{Methods}

\section{Study design, setting, period and populations}

A prospective cohort longitudinal study was employed at Sawla General Hospital, Arba Minch General Hospital and Chencha district Hospital from first of March 2018 to 28th of February 2020. Among those hospitals, over four thousand newborns were delivered per year and more than 612 newborns were admitted to the neonatal intensive care unit (NICU) at each hospital.

Follow up was initiated at diagnosis of perinatal asphyxia from 1st March 2018 and the follow-up period was closed on 28th February 2020. The study subjects were followed until the age of 7 days and it was closed if the newborn died or censored.

In this study, a newborn that withdrew treatment, discharged with recovery, transferred to another institution, and who did not yet develop the event at the end of the follow-up period was operationally defined as Censored. Sample size was estimated by Open Epi 3.02 statistical software using double population proportion formula in considering the assumptions; 95\% CI, 80\% power, exposed to unexposed ratio: 1 , percent of unexposed with outcome (Not having history of premature rupture of membrane (PROM)): $50 \%$, percent of exposed with outcome (prolonged labor): 62\%, AHR: 1.6 [14] and considering $10 \%$ for non-response, the sample size became 573. Sample size was allocated to each hospital proportionally based on the number of the admitted cases and consecutive sampling method was applied (Fig. 1).

\section{Study variables}

The dependent variable was time to perinatal mortality and the independent variables were classified as sociodemographic factors (sex of the newborn, maternal age, marital status, a religion of the mother, maternal educational status, maternal occupational status, family size, place of residence, distance between home and hospital and estimated monthly income), obstetrics related characteristics (number of antenatal care (ANC) visits, gravidity, parity, number of pervaginal examinations, history of meconium-stained amniotic fluid, the onset of labor, history of antepartum hemorrhage, history of obstructed labor, history of premature rupture of membrane, history of prolonged rupture of membrane, cord prolapse, presentation of the fetus, mode of delivery and gestational age), newborn related factors (cry immediately at birth, history of convulsion or spasm and birth weight) and maternal medical related characteristics (history of PIH, maternal iron deficiency anemia, maternal diabetes mellitus, and maternal HIV status).

\section{Operational definitions}

Perinatal asphyxia was diagnosed when the newborn had at least one of the following signs: not breathing or gasping, < 30 breaths per minute, or $<7$ APGAR score, had neonatal neurologic sequelae (seizures, coma, and hypotonia), or multiple organ involvement (kidney, lungs, liver, heart, and intestines) [10].

Maternal Anemia: Hemoglobin levels of less than $11 \mathrm{~g} /$ dl during the first and third trimesters and less than $10.5 \mathrm{~g} / \mathrm{dl}$ during the second trimester [15]. 


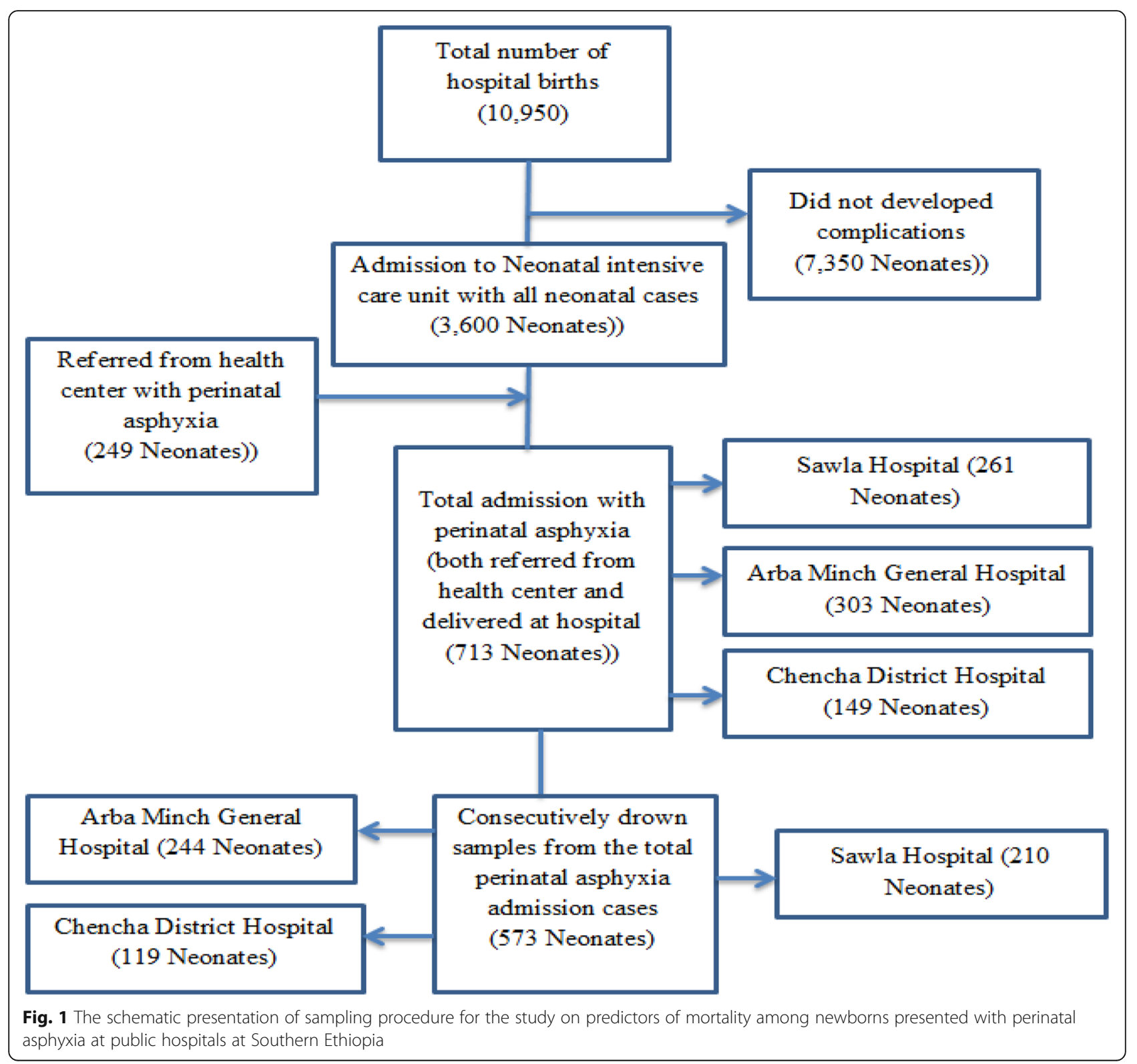

Premature rupture of the membrane: a rupture (breaking open) of the membranes (amniotic sac) before labor begins [16].

Prolonged rupture of membrane: a rupture of membranes lasting longer than $18-24 \mathrm{~h}$ (i.e., between the time of rupture and time of delivery) [16].

Convulsion: newborn who experience an episode of rigidity and uncontrolled jerky motions that generally last a minute or two along with altered consciousness [17].

\section{Data collection procedure}

Structured checklist was used to collect the data. Data extraction tool was carefully designed to improve data quality. In addition; both data collectors and supervisors were trained.

\section{Data quality control}

Pretest was conducted on 29 neonates at Ottona teaching and referral hospital before the actual data collection was initiated and the tool was revised to make it is consistent. The maternal hemoglobin test results were obtained from a laboratory report which was prepared for this research purpose. The hemoglobin level was adjusted for altitude according to criteria set by WHO (World health organization).

\section{Data processing and analysis}

Epi Data version 3.02 was used to enter the data, code the data, edit the data and clean the data. Finally, the data were entered in to Epi Data were exported to SPSS version 25 for statistical analysis. The Kaplan Meier 
survival curve, together with a log-rank test, was used to estimate the survival time and the time which had higher risk of death. Variables that had a $p$-value $<0.05$ in bivariate analysis were considered as candidates for multivariable analysis and variables which had a $p$-value < 0.05 in multivariable cox proportional hazard model were considered as statistically significant.

\section{Results}

The survival status of newborns with perinatal asphyxia In this study, among a total of 713 newborns, 573 consecutively predetermined samples of newborns were involved. Among them, 45(7.85\%) of the newborns with perinatal asphyxia died and 531 (92.67\%) were recovered. Among newborns admitted with perinatal asphyxia 27 (4.71\%) died in the first follow up day, which is $60 \%$ of the observed deaths within the study period. Similarly, the proportion of death at the second and third followup days was 2.09 and $0.52 \%$ respectively. There was no observed death after the fourth follow-up (Fig. 2).

The cumulative proportion of survival among the newborns admitted with perinatal asphyxia was 95.21\% (95\%CI: 91.00, 97.48) at the end of the first follow-up day. In addition, it was $92.82 \%$ (95\%CI: 87.95, 95.77), 92.02\% (95\%CI: $86.84,95.22)$ and $90.78 \%$ (95\%CI: 84.82,
94.48) at the end of the second, third, and fourth followup days respectively. As we have seen from Fig. 2, there was a rapid decline of survival on the first day and it became slow in the corresponding follow-up days. The overall mean survival time was 6.55 (95\%CI: 6.33, 6.77) (Fig. 3).

\section{Socio-demographic characteristics}

In this study a total of 573 newborns were involved, of which $351(61.3 \%)$ of them were males. In considering maternal age maximum of the mothers $(70.7 \%)$ were categorized as under 20-34 years of age and the smallest amount $(13.6 \%)$ were mothers having age less than 20 years old. Equal numbers of mothers were both unable to read and write and college and above, each accounted for $11 \%$ of the whole mothers. Among the dead newborns, $33.3 \%$ of mothers were urban residents and $66.7 \%$ were rural residents.

In considering the maternal khat chewing and alcohol consumption habits, $18(7.9 \%)$ of the mothers had a habit of khat chewing and similar proportions $(7.9 \%)$ of the mothers had a habit of alcohol consumption. In addition, one newborn was died among the khat chewer mothers, which accounts for $6.7 \%$ of the dead newborns. Similarly, one newborn with perinatal asphyxia was died

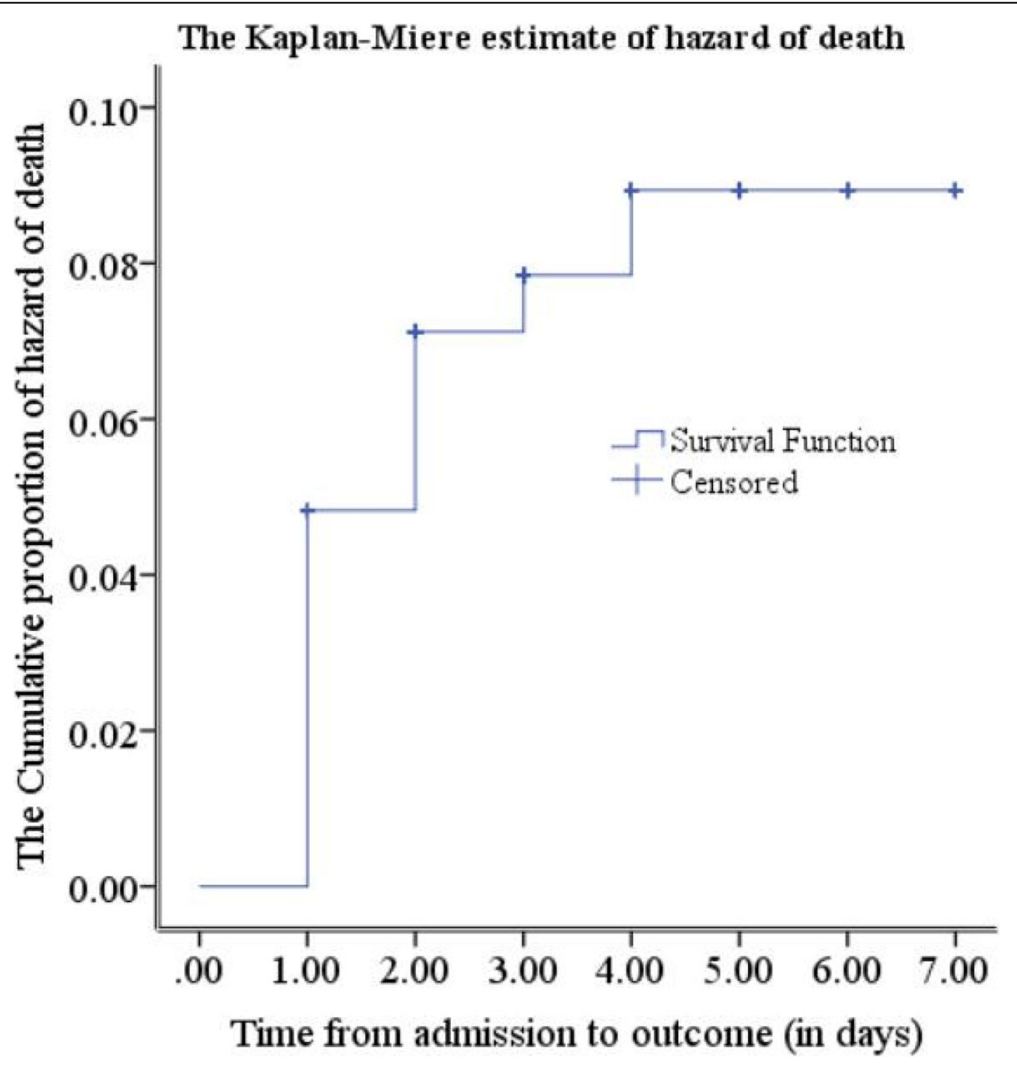

Fig. 2 The Kaplan Meier estimate of hazard of death among newborns admitted with perinatal asphyxia 


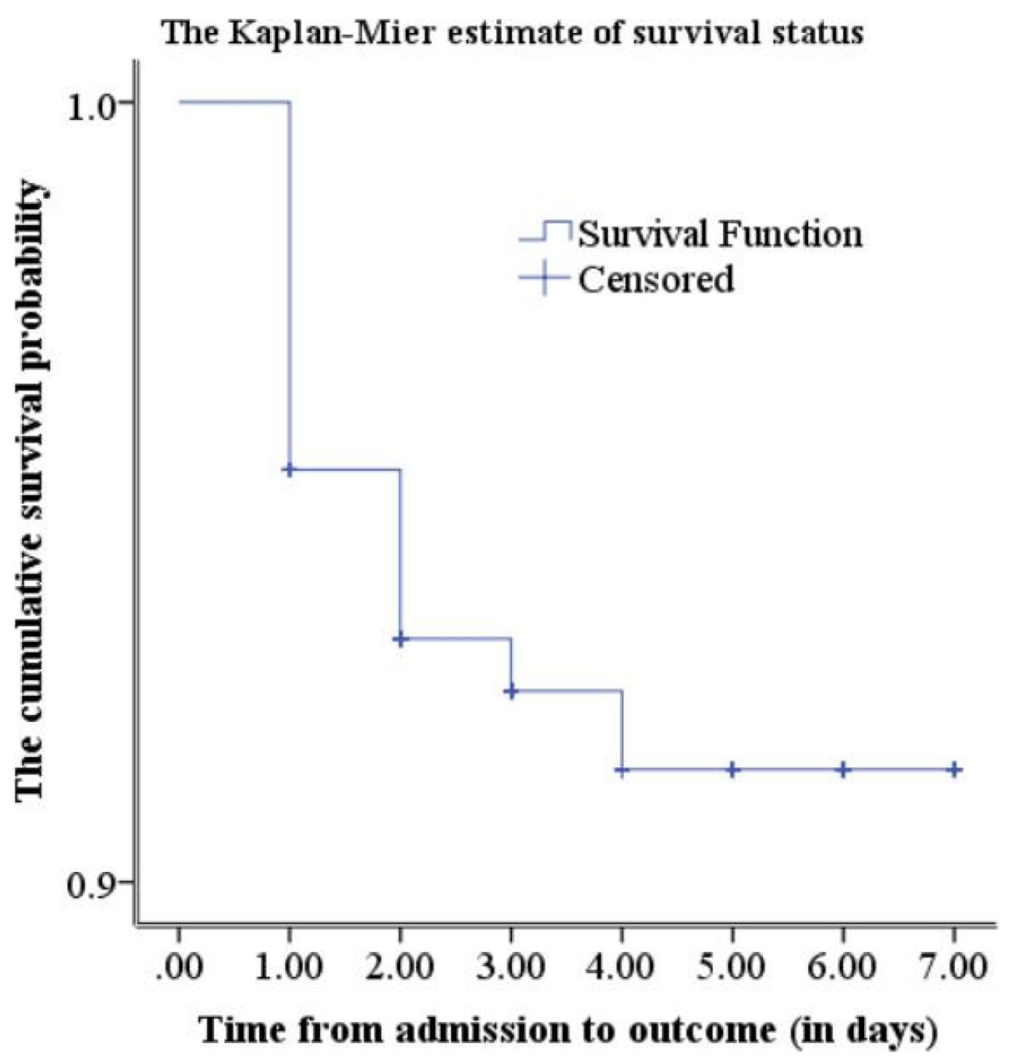

Fig. 3 The Kaplan Meier estimate of the survival function among newborns admitted with perinatal asphyxia

among the mothers who had a history of alcohol intake, which accounts for $6.7 \%$ of the dead newborns with perinatal asphyxia (Table 1).

\section{Obstetric related characteristics}

In this study, $81(14.1 \%)$ of the mothers had no antenatal visits. In addition; 207(36.1\%), 87(15.2\%), $78(13.6 \%)$, and $120(20.9 \%)$ of the mothers had one, two, three, and four antenatal visits, respectively. Regarding the number of pervaginal examinations, 351(61.3\%) of the mothers had one to three pervagninal examinations. Among the respondents, 465(81.2\%), 60(10.5\%), $114(19.9 \%), 129(22.5 \%)$ and $120(20.9 \%)$ of the newborn's mother faced the spontaneous onset of labor, obstructed labor, prolonged labor, PROM, and prolonged rupture of membranes, respectively.

Nearly one fifths $(21.5 \%)$ of the newborns were delivered at the health center. In considering complications during delivery, 102(17.8\%) of the newborns with perinatal asphyxia had cord prolapse, and $129(22.5 \%)$ of the newborns present with breech presentation. In addition, 408(71.2\%), 117(20.4\%), and 48(8.4) of the newborns were delivered by SVD and assisted instrumental and cesarean sections, respectively (Table 2).

\section{Newborn related characteristics and medical related characteristics of the mother}

Nearly half $(50.8 \%)$ of the newborns were delivered at gestational age, less than 37 weeks and $72(12.6 \%)$ of them were post terms (gestational age more than 42 weeks). All of the newborns were resuscitated immediately at birth by trained health professionals and $471(82.2 \%)$ of the newborns did not cry during birth. In this study, $165(28.8 \%), \quad 105(18.3 \%), 18(3.1 \%)$ and $30(5.2 \%)$ of the mothers had a history of diagnosed PIH, iron deficiency anemia, DM and HIV respectively (Table 3).

\section{Log rank estimate of the covariates of variables}

The Kaplan Meier survival curve together with the logrank test estimates the chi square and $p$-value of each variable. Distance between home and hospital, referral status of the newborn, meconium-stained amniotic fluid, obstructed labor, premature rupture of membrane, prolonged rupture of membrane, cord prolapse, presentation, place of delivery, mode of delivery, history of convulsion or spasm, birth weight, pregnancy-induced hypertension, and iron deficiency anemia were candidate variables for multivariable analysis in cox proportional hazard model (Table 4). 
Table 1 Socio-demographic characteristics of mothers of the newborn with perinatal asphyxia

\begin{tabular}{|c|c|c|c|}
\hline \multirow[t]{3}{*}{ Variables } & \multirow[t]{3}{*}{ Category } & \multicolumn{2}{|c|}{ Status of the newborn } \\
\hline & & Died & Survived \\
\hline & & $n(\%)$ & $\mathrm{n}(\%)$ \\
\hline \multirow[t]{2}{*}{ Sex } & Male & $27(60 \%)$ & $324(61.4 \%)$ \\
\hline & Female & $18(40 \%)$ & $204(38.6 \%)$ \\
\hline \multirow[t]{3}{*}{ Maternal age } & $<20$ & $9(20 \%)$ & $69(13.1 \%)$ \\
\hline & $20-34$ & $15(33.3 \%)$ & $390(73.9 \%)$ \\
\hline & $>35$ & $21(46.7 \%)$ & $69(13.1 \%)$ \\
\hline \multirow[t]{2}{*}{ Marital status } & Not married & $30(66.7 \%)$ & $21(4.0 \%)$ \\
\hline & Married & 15 (33.3\%) & $507(96.0 \%)$ \\
\hline \multirow[t]{4}{*}{ Religion } & Orthodox & $21(46.7 \%)$ & $228(43.2 \%)$ \\
\hline & Muslim & $6(13.3 \%)$ & $105(19.9 \%)$ \\
\hline & Protestant & $18(40.0 \%)$ & $165(31.3 \%)$ \\
\hline & Others & $0(0.00 \%)$ & $30(5.7 \%)$ \\
\hline \multirow[t]{5}{*}{ Educational status of the mother } & Unable to read and write & $9(20.0 \%)$ & $54(10.2 \%)$ \\
\hline & Able to read and write & $12(26.7 \%)$ & $105(19.9 \%)$ \\
\hline & Grade 1-8 & $9(20.0 \%)$ & $207(39.2 \%)$ \\
\hline & Grade 9-12 & $9(20.0 \%)$ & $105(19.9 \%)$ \\
\hline & College and above & $6(13.3 \%)$ & $57(10.8 \%)$ \\
\hline \multirow[t]{5}{*}{ Occupational status of the mother } & House wife & $9(20.0 \%)$ & $42(8.0 \%)$ \\
\hline & Self-employee & $12(26.7 \%)$ & $120(22.7 \%)$ \\
\hline & Farmers & $9(20.0 \%)$ & $198(37.5 \%)$ \\
\hline & Merchant & $9(20.0 \%)$ & $117(22.2 \%)$ \\
\hline & Civil servant & $6(13.3 \%)$ & $51(9.7 \%)$ \\
\hline \multirow[t]{3}{*}{ Family size } & $<4$ & $9(20.0 \%)$ & $264(50.0 \%)$ \\
\hline & $4-6$ & $15(33.3 \%)$ & $177(33.5 \%)$ \\
\hline & $>6$ & $21(46.7 \%)$ & $87(16.5 \%)$ \\
\hline \multirow[t]{2}{*}{ Place of residence } & Urban & $15(33.3 \%)$ & $423(80.1 \%)$ \\
\hline & Rural & $30(66.7 \%)$ & $105(19.9 \%)$ \\
\hline \multirow[t]{2}{*}{ Distance b/n home and hospital } & $<10 \mathrm{~km}$ & $9(20.0 \%)$ & $357(62.3 \%)$ \\
\hline & $>10 \mathrm{~km}$ & $36(80 \%)$ & $216(37.7 \%)$ \\
\hline \multirow[t]{4}{*}{ Estimated monthly income (ETB) } & $<1399$ & $18(40.0 \%)$ & $36(6.8 \%)$ \\
\hline & 1400-1999 & $9(20.0 \%)$ & $114(21.6 \%)$ \\
\hline & $2000-2599$ & $9(20.0 \%)$ & $189(35.8 \%)$ \\
\hline & $>2600$ & $9(20.0 \%)$ & $189(35.8 \%)$ \\
\hline
\end{tabular}

The mean survival time among the covariates of predictors of mortality

The mean survival time was different among the covariates of each predictor. The mean survival time was higher among the newborns that had no cord prolapse as compared with those who had cord prolapse during delivery. Similarly, the average survival time was higher among newborns born with a mother who had no pregnancy-induced hypertension and no diagnosed iron deficiency anemia as compared with those with pregnancy-induced hypertension and iron deficiency anemia respectively (Table 5).
Predictors of mortality among newborns with perinatal asphyxia

In this study, cord prolapse, pregnancy induced hypertension, iron deficiency anemia of the mother and having a history of convulsion or spasm of the newborn were statistically significant in the multivariable cox regression model.

Newborns having cord prolapse during delivery had six times higher risk of mortality as compared with those who had no cord prolapse (AHR: 6.5; 95\%CI: 1.18, 36.01). The risk of mortality among newborns with 
Table 2 Obstetric related characteristics of the newborns with perinatal asphyxia

\begin{tabular}{|c|c|c|c|}
\hline \multirow[t]{3}{*}{ Variables } & \multirow[t]{3}{*}{ Category } & \multicolumn{2}{|c|}{ Status of the newborn } \\
\hline & & Died & Survived \\
\hline & & $\mathrm{n}(\%)$ & $\mathrm{n}(\%)$ \\
\hline \multirow[t]{5}{*}{ Number of ANC visits } & No & $18(60.0 \%)$ & $54(10.2 \%)$ \\
\hline & One & $9(20.0 \%)$ & $198(37.5 \%)$ \\
\hline & Two & $3(6.7 \%)$ & $84(15.9 \%)$ \\
\hline & Three & $3(6.7 \%)$ & 75 (14.2\%) \\
\hline & Four and above & $3(6.7 \%)$ & $117(22.2 \%)$ \\
\hline \multirow[t]{2}{*}{ Gravidity } & Primigravida & $6(13.3 \%)$ & $171(32.4 \%)$ \\
\hline & Multigravida & $39(86.7 \%)$ & $357(67.6 \%)$ \\
\hline \multirow[t]{3}{*}{ Parity } & Primipara & $3(6.7 \%)$ & $144(27.3 \%)$ \\
\hline & 2-4 birth & $15(33.3 \%)$ & $159(30.1 \%)$ \\
\hline & Five and above births & $27(60.0 \%)$ & $225(42.6 \%)$ \\
\hline \multirow[t]{2}{*}{ Number of pervaginal examinations } & $1-3$ & $21(46.7 \%)$ & $330(62.5 \%)$ \\
\hline & Four and above & $24(53.3 \%)$ & $198(37.5 \%)$ \\
\hline \multirow[t]{2}{*}{ History of Meconium stained amniotic fluid } & Yes & $36(80.0 \%)$ & $78(14.8 \%)$ \\
\hline & No & $9(20.0 \%)$ & $450(85.2 \%)$ \\
\hline \multirow[t]{2}{*}{ Onset of labor } & Spontaneous & $36(80.0 \%)$ & $429(81.3 \%)$ \\
\hline & Induced & $9(20.0 \%)$ & 99 (18.8\%) \\
\hline \multirow[t]{2}{*}{ Antepartum hemorrhage } & Yes & $12(26.7 \%)$ & $120(22.7 \%)$ \\
\hline & No & $33(73.3 \%)$ & $408(77.3 \%)$ \\
\hline \multirow[t]{2}{*}{ Obstructed labor } & Yes & $18(60.0 \%)$ & $33(6.3 \%)$ \\
\hline & No & $18(40.0 \%)$ & $495(93.8 \%)$ \\
\hline \multirow[t]{2}{*}{ Duration of labor (hrs) } & Less than 18 & $33(73.3 \%)$ & $81(15.3 \%)$ \\
\hline & Greater than 18 & $12(26.7 \%)$ & $447(84.7 \%)$ \\
\hline \multirow[t]{2}{*}{ Premature rupture of membrane } & Yes & $30(66.7 \%)$ & 99 (18.8\%) \\
\hline & No & $15(33.3 \%)$ & $429(81.3 \%)$ \\
\hline \multirow[t]{2}{*}{ Prolonged rupture of membrane } & Yes & $33(73.3 \%)$ & $87(16.5 \%)$ \\
\hline & No & $12(26.7 \%)$ & $441(83.5 \%)$ \\
\hline \multirow[t]{2}{*}{ Cord prolapse } & Yes & $33(73.3 \%)$ & $63(13.1 \%)$ \\
\hline & No & $12(26.7 \%)$ & $459(86.7 \%)$ \\
\hline \multirow[t]{2}{*}{ Presentation } & Cephalic & $15(33.3 \%)$ & $429(81.3 \%)$ \\
\hline & Breech & $30(66.7 \%)$ & $99(18.8 \%)$ \\
\hline \multirow[t]{3}{*}{ Mode of delivery } & Spontaneous vaginal delivery & $18(40.0 \%)$ & $390(73.9 \%)$ \\
\hline & Assisted instrumental & $21(46.7 \%)$ & 96 (18.2\%) \\
\hline & Cesarean section & $6(13.3 \%)$ & $42(8.0 \%)$ \\
\hline \multirow[t]{3}{*}{ Gestational age (week) } & $<37$ & $12(26.7 \%)$ & $279(52.8 \%)$ \\
\hline & $37-42$ & $12(26.7 \%)$ & $198(37.5 \%)$ \\
\hline & $>42$ & $21(46.75)$ & $51(9.7 \%)$ \\
\hline
\end{tabular}

perinatal asphyxia and delivered with mothers who had a history of pregnancy induced hypertension was 25 times higher as compared with those who had no pregnancy induced hypertension (AHR: 25.4; 95\%CI: 3.68, 175.0).
Newborns with perinatal asphyxia and delivered with mothers with iron deficiency anemia had five times higher risk mortality as compared with those mothers who had no iron deficiency anemia (AHR: 5.9; 95\%CI: 1.19, 29.5). Newborns admitted with perinatal asphyxia 
Table 3 Newborn related and maternal medical disorders affecting the survival status of the newborns with perinatal asphyxia

\begin{tabular}{llll}
\hline Variable & Category & \multicolumn{2}{l}{ Status of the newborn } \\
\cline { 2 - 4 } & & Died & Survived \\
& & $\mathbf{n}(\%)$ & $\mathbf{n}(\%)$ \\
\hline Cry immediately at birth & Yes & $3(6.7 \%)$ & $99(18.8 \% \%)$ \\
History of convulsion or spasm & Yes & $42(93.3 \%)$ & $429(81.3 \%)$ \\
& No & $33(73.3 \%)$ & $519(98.3 \%)$ \\
Birth weight (gram) & $<2500$ & $30(66.7 \%)$ & $156(29.5 \%)$ \\
& $\geq 2500$ & $15(33.3 \%)$ & $372(70.5 \%)$ \\
Pregnancy induced hypertension & Yes & $36(80.0 \%)$ & $129(24.4 \%)$ \\
Maternal Iron deficiency anemia & Yes & $9(20.0 \%)$ & $399(75.6 \%)$ \\
& No & $21(53.3 \%)$ & $81(15.3 \%)$ \\
Maternal Diabetes mellitus & Yes & $3(6.7 \%)$ & $15(2.8 \%)$ \\
& No & $42(93.3 \%)$ & $513(97.2 \%)$ \\
HIV status & Positive & $3(6.7 \%)$ & $27(5.1 \%)$ \\
& Negative & $42(93.3 \%)$ & $501(94.9 \%)$ \\
\hline
\end{tabular}

and had history of convulsion or spasm had 10 times higher risk of mortality as compared with those who had no history of convulsion of spasm (AHR: 10.23; 95\%CI: 2.24, 46.54) (Table 6).

\section{Discussion}

This study assesses the predictors of mortality among newborns admitted with perinatal asphyxia at public hospitals in Southern Ethiopia and it showed there was a high proportion of mortality at the early admission periods especially at the first day and gradually declines as the follow-up period has been increased.

Newborns having cord prolapse during delivery had six times higher risk of mortality as compared with those who had no cord prolapse (AHR: 6.5; 95\%CI: 1.18, 36.01). This study finding is similar with the study conducted in Karachi, Pakistan [2]. The principal causes of perinatal asphyxia in this context was thought to be cord compression and umbilical arterial vasospasm which prevents venous and arterial blood flow to and from the fetus. In addition; it can predispose other factors that lead the newborn to die such as assisted ventilation requirement, low cord $\mathrm{pH}$, meconium aspiration, hyaline membrane disease, convulsion, neonatal encephalopathy, and cerebral palsy $[16,18]$.

Consistent with the study conducted at Dilla University referral hospital, Southern Ethiopia, Tigray regional state, Ethiopia and tertiary care center in Ahmedabad, Gujarat, India and Ayder comprehensive specialized hospital, Northern Ethiopia [19-22], the risk of mortality
Table 4 The log rank estimate of the variables determining the survival status among newborns admitted with perinatal asphyxia

\begin{tabular}{|c|c|c|}
\hline \multirow[t]{2}{*}{ Variables } & \multicolumn{2}{|c|}{ Log rank estimate } \\
\hline & Chi square $\left(X^{2}\right)$ & $P$-value \\
\hline Sex & 0.003 & 0.959 \\
\hline Maternal age & 1.365 & 0.81 \\
\hline Marital status & 3.85 & 0.64 \\
\hline Religion & 1.48 & 0.68 \\
\hline Educational status of the mother & 2.97 & 0.56 \\
\hline Occupational status of the mother & 3.73 & 0.44 \\
\hline Family size & 2.21 & 0.310 \\
\hline Place of residence & 1.79 & 0.32 \\
\hline Distance between home and hospital & 20.05 & 0.0001 \\
\hline Referral status & 26.02 & 0.0001 \\
\hline Estimated monthly income (ETB) & 1.89 & 0.53 \\
\hline Maternal Khat chewing status & 0.089 & 0.765 \\
\hline Alcohol intake & 0.031 & 0.86 \\
\hline Number of ANC visits & 3.09 & 0.74 \\
\hline Gravidity & 2.31 & 0.129 \\
\hline Parity & 3.27 & 0.194 \\
\hline Number of pervaginal examinations & 1.43 & 0.23 \\
\hline Meconium stained amniotic fluid & 37.04 & 0.0001 \\
\hline Onset of labor & 0.005 & 0.94 \\
\hline Antepartum hemorrhage & 0.134 & 0.715 \\
\hline Obstructed labor & 43.79 & 0.0001 \\
\hline Duration of labor & 5.43 & 0.631 \\
\hline Premature rupture of membrane & 17.9 & 0.0001 \\
\hline Prolonged rupture of membrane & 28.35 & 0.0001 \\
\hline Cord prolapse & 35.44 & 0.0001 \\
\hline Presentation & 18.40 & 0.0001 \\
\hline Place of delivery & 26.02 & 0.0001 \\
\hline Mode of delivery & 8.36 & 0.015 \\
\hline Gestational age & 0.48 & 0.487 \\
\hline Cry immediately at birth & 1.38 & 0.239 \\
\hline History of convulsion or spasm & 26.32 & 0.0001 \\
\hline Birth weight (gram) & 8.94 & 0.003 \\
\hline Pregnancy induced hypertension & 21.12 & 0.0001 \\
\hline Maternal Iron deficiency anemia & 13.15 & 0.0001 \\
\hline Maternal Diabetes mellitus & 0.733 & 0.392 \\
\hline Maternal HIV status & 0.07 & 0.79 \\
\hline
\end{tabular}

among newborns with perinatal asphyxia and delivered with mothers who had a history of pregnancy induced hypertension was 25 times higher as compared with those who had no pregnancy-induced hypertension (AHR: 25.4; 95\%CI: 3.68, 175.0). This might be related to the effect of diminished uteroplacental blood flow and 
Table 5 The mean survival date estimate of the newborns with perinatal asphyxia among the covariates of predictors

\begin{tabular}{lll}
\hline Variables & Category & $\begin{array}{l}\text { Mean survival time } \\
\mathbf{( 9 5 \% C l )}\end{array}$ \\
\hline Cord prolapse & Yes & $5.19(4.31,6.07)$ \\
& No & $6.85(6.70,6.99)$ \\
Pregnancy induced & Yes & $5.76(5.14,6.38)$ \\
hypertension & No & $6.87(6.73,7.01)$ \\
Iron deficiency anemia & Yes & $5.72(4.94,6.50)$ \\
& No & $6.74(6.56,6.93)$ \\
Convulsion or spasm & Yes & $3.04(2.07,4.02)$ \\
& No & $6.65(6.45,6.85)$ \\
\hline
\end{tabular}

placental ischemia, which can be due to pregnancyinduced hypertension which reduces blood flow to the fetus $[23,24]$. In addition; pregnancy-induced hypertension (PIH) has an effect on the reduction of blood supply, nutrients, and oxygen to the fetus at intrauterine life, finally which ends up in intrauterine growth restriction. This condition can contribute to newborn mortality with perinatal asphyxia [25].

Newborns with perinatal asphyxia and delivered by mothers who have iron deficiency anemia had five times higher risk mortality as compared with the counterparts who had no iron deficiency anemia (AHR: 5.9; 95\%CI: $1.19,29.5)$. This study finding is concise with the study done at Dilla University referral hospital, Southern Ethiopia, Southern Nations Nationalities and Peoples

Table 6 Predictors of mortality among newborns admitted with perinatal asphyxia

\begin{tabular}{|c|c|c|c|c|c|}
\hline \multirow[t]{2}{*}{ Variables } & \multirow[t]{2}{*}{ Category } & \multicolumn{2}{|c|}{ Status } & \multirow[t]{2}{*}{ COR(95\%Cl) } & \multirow[t]{2}{*}{ AOR(95\%Cl) } \\
\hline & & Died & Survived & & \\
\hline \multirow[t]{2}{*}{ Distance $b / n$ home and hospital } & $<10 \mathrm{~km}$ & 3 & 119 & 1 & 1 \\
\hline & $>10 \mathrm{~km}$ & 27 & 84 & $8.24(2.36,14.12)^{a}$ & $2.41(0.96,3.86)$ \\
\hline \multirow[t]{2}{*}{ Referral status } & Yes & 11 & 30 & $10.52(3.34,33.05)^{a}$ & $0.65(0.02,16.62)$ \\
\hline & No & 4 & 146 & 1 & 1 \\
\hline \multirow[t]{2}{*}{ Meconium stained amniotic fluid } & Yes & 12 & 26 & $16.95(4.78,60.12)^{\mathrm{a}}$ & $1.46(0.17,12.24)$ \\
\hline & No & 3 & 150 & 1 & 1 \\
\hline \multirow[t]{2}{*}{ Obstructed labor } & Yes & 9 & 11 & $13.76(4.89,38.69)^{a}$ & $0.48(0.02,7.87)$ \\
\hline & No & 6 & 165 & 1 & 1 \\
\hline \multirow[t]{2}{*}{ Premature ROM } & Yes & 10 & 33 & $7.08(2.42,20.72)^{a}$ & $1.54(0.20,11.90)$ \\
\hline & No & 5 & 143 & 1 & 1 \\
\hline \multirow[t]{2}{*}{ Prolonged ROM } & Yes & 11 & 29 & $11.34(3.60,35.70)^{a}$ & $0.50(0.02,10.84)$ \\
\hline & No & 4 & 147 & 1 & 1 \\
\hline \multirow[t]{2}{*}{ Cord prolapse } & Yes & 11 & 23 & $13.68(4.35,43.02)^{a}$ & $6.5(1.18,36.01)^{b}$ \\
\hline & No & 4 & 153 & 1 & 1 \\
\hline \multirow[t]{2}{*}{ Presentation } & Cephalic & 5 & 143 & 1 & 1 \\
\hline & Breech & 10 & 33 & $7.22(2.46,21.14)^{\mathrm{a}}$ & $4.1(0.91,18.54)$ \\
\hline \multirow[t]{2}{*}{ Place of delivery } & Health center & 11 & 30 & $10.52(3.34,33.05)^{a}$ & $6.4(0.73,6.82)$ \\
\hline & Hospital & 4 & 146 & 1 & 1 \\
\hline \multirow[t]{2}{*}{ Birth weight (gram) } & $<2500$ & 10 & 52 & $2.09(1.22,3.58)^{a}$ & $2.99(0.73,12.13)$ \\
\hline & $>2500$ & 5 & 124 & 1 & 1 \\
\hline \multirow[t]{2}{*}{ Pregnancy induced hypertension } & Yes & 12 & 43 & $3.23(1.71,6.09)^{a}$ & $25.4(3.68,175.0)^{b}$ \\
\hline & No & 3 & 133 & 1 & 1 \\
\hline \multirow[t]{2}{*}{ Maternal Iron deficiency anemia } & Yes & 8 & 27 & $2.28(1.37,3.79)^{a}$ & $5.9(1.19,29.5)^{b}$ \\
\hline & No & 7 & 149 & 1 & 1 \\
\hline \multirow[t]{3}{*}{ Mode of delivery } & SVD & 6 & 130 & 1 & 1 \\
\hline & Assisted instrumental & 7 & 32 & $4.2(1.4,12.65)^{a}$ & $0.87(0.15,5.12)$ \\
\hline & $\mathrm{CS}$ & 2 & 14 & $2.96(0.59,14.70)$ & $5.86(0.84,40.77)$ \\
\hline \multirow[t]{2}{*}{ Convulsion } & Yes & 4 & 3 & $3.27(1.84,5.82)^{a}$ & $10.23(2.24,46.54)^{b}$ \\
\hline & No & 11 & 173 & 1 & 1 \\
\hline
\end{tabular}


Regional State of Ethiopia and Jimma Zone, Southwest Ethiopia [16, 26, 27].

Newborns admitted with perinatal asphyxia and had a history of convulsion of spasm had a 10 times higher risk of mortality as compared with those who had no history of convulsion of spasm (AHR: 10.23; 95\%CI: $2.24,46.54)$. The possible reason might be convulsion that may cause the newborn to cease breathing (apnea). If this interruption in breathing persists, it can result in a decline in oxygen saturation in the blood to a lifethreatening level.

Irrespective of the study conducted at Southern Nepal, Ayder comprehensive specialized hospital, Dilla University referral hospital, primiparity, place of delivery, multi-parity, low birth weight, mode of delivery and premature rupture of the membrane was not statistically significant predictors of mortality [19, 28-30].

\section{Limitation of the study}

Since the study was conducted among the newborns delivered at public hospitals, it cannot be generalized for the newborns delivered at home, health centers and health posts. In addition, this study did not assess the complications secondary to perinatal asphyxia.

\section{Conclusion}

The survival status of newborns admitted with perinatal asphyxia was low at the early follow up periods after admission to the hospital and the survival status improved at the later follow up periods. In addition, having cord prolapse of the newborn during delivery, maternal history of pregnancy-induced hypertension, maternal history of iron deficiency anemia and newborn history of convulsion or spasm were the independent predictors of mortality.

\section{Abbreviations}

AHR: Adjusted hazard ratio; ANC: Antenatal Care; APGAR: Appearance, pulse, Grimace, Activity and Respiratory effort; APH: Antepartum hemorrhage; CHR: Crude hazard ratio; DM: Diabetes mellitus; PIH: Pregnancy induced hypertension; WHO: World Health Organization

\section{Acknowledgements}

We would like to thank the mothers who are directly involved in the study and administrator of each hospital for their effort and permission to conduct the study.

\section{Authors' contributions}

Samuel Dessu was involved in the conception, design, analysis, interpretation, report and manuscript writing. Zinabu Dawit, Abebe Timerga and Muluken Bafa were involved in the review of the design, analysis, interpretation and report writing. All authors read and approved the final manuscript.

\section{Funding}

Not applicable.

\section{Availability of data and materials}

The data sets generated and/or analyzed are available with a reasonable request through the corresponding author.

\section{Declarations}

Ethics approval and consent to participate

All methods were carried out in accordance with relevant quidelines and regulations. Ethical clearance was obtained from Arba Minch University, college of medicine and health sciences ethical review board. All participants provided an informed consent. Mothers were informed about the objective and significance of the study prior to the data collection. Appropriate measures were applied to ensure the confidentiality of the data.

Consent for publication

Not applicable.

\section{Competing interests}

All the authors declare that there is no any conflict of interest.

\section{Author details}

'Department of Public Health, College of Medicine and Health Sciences, Wolkite University, Wolkite, Ethiopia. ${ }^{2}$ Department of Nursing, Arba Minch Health Science College, Arba Minch, Ethiopia. ${ }^{3}$ Department of Biomedical sciences, College of Medicine and Health Sciences, Wolkite University, Wolkite, Ethiopia.

Received: 29 January 2021 Accepted: 8 June 2021

Published online: 07 July 2021

\section{References}

1. Pitsawong C, Panichkul P. Risk factors associated with birth asphyxia in Phramongkutklao hospital. Thai J Obstet Gynaecol. 2012;19(4):165-71.

2. Ekwochi U, Asinobi NI, Osuorah CDI, Ndu IK, Ifediora C, Amadi OF, et al. Incidence and predictors of perinatal asphyxia: a 4-year prospective study of newborns delivered in health care facilities in Enugu, south-west Nigera. Clin Med Insights. 2017;11:1-10.

3. Bryce J, Boschi-Pinto C, Shibuya K, Black RE. WHO estimates of the causes of death in children. Lancet. 2005;365(9465):1147-52.

4. World Health Organization. Newborns: reducing mortality, 2018. Available: https://www.who.int/newsroom/fact-sheet/detail, Accessed 2 May 2018.

5. Joy Lawn PM, Cousens $S$. Africa's newborns-counting them and making them count. Opportunities for Africa's Newborns; 2010.

6. Birth Asphyxia - Summary of the previous meeting and protocol overview http://www.curoservice.com/health_professionals/news/pdf/10-09-2007_ birth asphyxia02.pdf.

7. State of the World's Children, UNICEF; 2009 .

8. World Health Organization. GUIDELINE ON BASIC NEWBORN RESUSCITATION, 2012. Available: https:/www.who.int/maternal_child_adolescent/documents/basic_ newborn_resuscitation/en, Accessed 5 Apr 2018.

9. Bayih WA, Yitbarek GY, Aynalem YA, et al. Prevalence and associated factors of birth asphyxia among live births at Debre Tabor general hospital, north Central Ethiopia. BMC Pregnancy Childbirth. 2020;20:653. https://doi.org/1 0.1186/s12884-020-03348-2.

10. Desalew A, Sintayehu Y, Teferi N, et al. Cause and predictors of neonatal mortality among neonates admitted to neonatal intensive care units of public hospitals in eastern Ethiopia: a facility-based prospective follow-up study. BMC Pediatr. 2020;20:160. https://doi.org/10.1186/s12887-020-02051-7.

11. Federal Minstry of Health. Health Sector Transformation Plan (HSTP 20162020). Addis Ababa: FMOH; 2015.

12. Federal Minstry of Health. Neonatal Intensive Care Unit (NICU) Training: Management Protocol. Addis Ababa: FMO; 2014.

13. Abdo RA, Halil HM, Kebede BA, et al. Prevalence and contributing factors of birth asphyxia among the neonates delivered at Nigist Eleni Mohammed memorial teaching hospital, Southern Ethiopia: a cross-sectional study. BMC Pregnancy Childbirth. 2019;19:536. https://doi.org/10.1 186/s12884-019-2696-6.

14. Kebede EB, Akuma AO, Tarfa YB. Perinatal Asphyxia among neonates admitted Jimma Medical Center, vol. 7; 2020. p. 1-5.

15. Heba OO, Ibrahim AA, AAM O. Hemoglobin and iron levels in normal nonpregnant and pregnant sudanese ladies in Khartoum State. J Gynecol Women's Health. 2018;12(5):555847. https://doi.org/10.19080/JGWH.2018.12.555847.

16. Mercer BM, Chien EKS. Premature rupture of the membranes. In: Resnick R, Lockwood CJ, Moore TR, Greene MF, Copel JA, Silver RM, editors. Creasy and Resnik's Maternal-Fetal Medicine: Principles and Practice. 8th ed. Philadelphia: Elsevier; 2019. p. chap 42. 
17. Samuel D, Mesfin K, Feleke G, Tadele G. Predictors of neonatal mortality among neonates who admitted in neonatal intensive care unit at Arba Minch general hospital. Ethiop J Health Dev. 2019;33(1):46-52.

18. Waleed ASA, Mostafa AH. Optimal management of umbilical cord prolapse. Int J Womens Health. 2018;10:459-65.

19. Murphy DJ, Mackenzie I. The mortality and morbidity associated with umbilical cord prolapse. Br J Obstet Gynaecol. 1995;102(10):826-30.

20. Abebe A, Getnet M, Gerezgiher BA, Ashenafi D. Prevalence and associated factors of perinatal asphyxia among newborns in Dilla University referral hospital, southern Ethiopia- 2017. Pediatric Health Med Ther. 2019;10:69-74.

21. Meghavini RP, Pradhyuman V. Effect of pregnancy induced hypertension on maternal and perinatal outcome at tertiary care center in Ahmedabad, Gujarat, India. Int J Reprod Contracept Obstetr Gynecol. 2017;6(10):4661-5.

22. Berhe AK, llesanmi AO, Aimakhu CO, et al. Effect of pregnancy induced hypertension on adverse perinatal outcomes in Tigray regional state, Ethiopia: a prospective cohort study. BMC Pregnancy Childbirth. 2020;20:7. https://doi.org/10.1186/s12884-019-2708-6.

23. Gebrehiwot TG, Fikaden BH, Haftom TA. Prevalence and associated factors of perinatal asphyxia in neonates admitted to ayder comprehensive specialized Hospital, Northern Ethiopia. Int J Pediatr. 2020;1-8.

24. Gilbert JS, Ryan MJ, LaMarca BB, Sedeek M, Murphy SR, Granger JP. Pathophysiology of hypertension during preeclampsia: linking placental ischemia with endothelial dysfunction. Am J Phys Heart Circ Phys. 2008; 294(2):H541-H50.

25. George IO, Jeremiah I. Perinatal outcome of babies delivered to eclamptic mothers: a prospective study from a Nigerian tertiary hospital. Int I Biomed Sci. 2009;5(4):390.

26. Yodit ZB, Abel GK, Letekirstos G, Natnael EA, Lidya ZB, Sumeya AM, et al. Risk factors of birth asphyxia among neonates born in public hospitals of Tigray, Northern Ethiopia. Pediatric Health Med Ther. 2020;11:13-20.

27. Bayou G, Berhan Y. Perinatal mortality and associated risk factors: a case control study. Ethiop J Health Sci. 2012;22(3):153-62.

28. Debelew GT, Afework MF, Yalew AW. Determinants and Causes of Neonatal Mortality in Jimma Zone, Southwest Ethiopia: A Multilevel Analysis of Prospective Follow Up Study. PLoS ONE. 2014;9(9):e107184. https://doi.org/1 0.1371/journal.pone.0107184.

29. Anne CCL, Luke CM, James MT, Joanne K, Subarna KK, Steven CL, et al. Risk factors for neonatal mortality due to birth asphyxia in southern Nepal. Pediatrics. 2008;121(5):e1381-e90.

30. Woday A, Muluneh A, St Denis C. Birth asphyxia and its associated factors among newborns in public hospital, northeast Amhara, Ethiopia. PLoS ONE. 2019;14(12):e0226891. https://doi.org/10.1371/journal.pone.0226891.

\section{Publisher's Note}

Springer Nature remains neutral with regard to jurisdictional claims in published maps and institutional affiliations.

Ready to submit your research? Choose BMC and benefit from:

- fast, convenient online submission

- thorough peer review by experienced researchers in your field

- rapid publication on acceptance

- support for research data, including large and complex data types

- gold Open Access which fosters wider collaboration and increased citations

- maximum visibility for your research: over $100 \mathrm{M}$ website views per year

At BMC, research is always in progress.

Learn more biomedcentral.com/submissions 